Original Research Paper

\title{
Keanekaragaman Jenis Kepiting di Ekosistem Hutan Mangrove Kuala Langsa, Kota Langsa, Aceh
}

\author{
Andika Putriningtias $^{1 *}$, Teuku Muhammad Faisal ${ }^{1}$, Siti Komariyah ${ }^{1}$, Syamsul Bahri ${ }^{2}$, Helmy Akbar ${ }^{1,3}$ \\ ${ }^{1}$ Program Studi Budidaya Perairan, Fakultas Pertanian, Universitas Samudra \\ Jl. Meurandeh, Langsa Lama, Kota Langsa. \\ ${ }^{2}$ Program Studi Agroteknologi, Fakultas Pertanian, Universitas Samudra \\ Jl. Meurandeh, Langsa Lama, Kota Langsa. \\ ${ }^{3}$ Program Studi Ilmu Kelautan, Fakultas Perikanan dan Ilmu kelautan, Universitas Mulawarman \\ Jl. Kampus Gunung Kelua, Kota Samarinda
}

\section{Article history}

Received: 07 Maret 2019

Revised: 27 Maret 2019

Accepted: 29 Maret 2019

Published: 01 April 2019

*Corresponding Author:

Andika Putriningtias,

Program Studi Budidaya

Perairan, Fakultas Pertanian,

Universitas Samudra

Email:

ika.andikaputri@gmail.com
Abstract : Mangrove is a vegetation that has many benefits. One of them, mangrove provide living space to many organism. Crabs are one of a wide variety of invertebrate animals that live in association with mangroves. The importance of the role of crabs in the mangrove ecosystem because the crab is a burrowing organism, so it will support the mangrove land becomes fertile. This study aims to determine the diversity of crabs, dominant or most commonly found crab species and crab living habitats associated with mangrove trees around Kuala Langsa mangrove forest, Langsa City, Aceh. This research is only descriptive. Sampling is done by 2 methods that is qualitative in quadrant plot $5 \times 5$ meter 2 and quantitative in quadrant plot $1 \times 1$ meter2. From the results of the study found 15 species of crabs from 7 genera and 5 families. The index value of diversity for all research stations was included in the medium category. The uniformity index is high and there is no type dominance on all stations. Of the 15 types of crabs, there are 3 types of economical crabs (Scylla serrata, Scylla olivacea and Thalamita crenata) and 12 types of non-economical crabs. In general, the crabs of the Genus Uca are the most commonly found crabs in the study sites.

Keywords: Aceh, Biodiversity, Crabs, Kuala Langsa, Mangrove

Abstrak : Mangrove merupakan suatu vegetasi yang memiliki banyak manfaat.Salah satu dari manfaat mangrove adalah menyediakan ruang hidup bagi banyak organisme.Kepiting merupakan salah satu dari berbagai jenis hewan avertebrata yang hidup berasosiasi dengan mangrove. Pentingnya peran kepiting pada ekosistem mangrove karena kepiting merupakan hewan yang hidup meliang, sehingga akan membuat tanah pada ekosistem mangrove menjadi subur. Penelitian ini bertujuan untuk mengetahui keanekaragaman jenis kepiting, jenis kepiting yang mendominasi atau paling sering ditemukan dan habitat hidup kepiting yang berasosiasi dengan pohon mangrove di sekitar hutan mangrove Kuala Langsa, Kota Langsa, Aceh.Penelitian ini bersifat deskriptif. Pengambilan sampel dilakukan dengan 2 metode yaitu kualitatif pada kuadran plot $5 \times 5$ meter $^{2}$ dan kuantitatif pada kuadran plot $1 \times 1$ meter $^{2}$. Dari hasil penelitian ditemukan 15 jenis kepiting dari 7 genus dan 5 famili.Nilai indeks keanekaragaman untuk semua stasiun penelitian termasuk dalam kategori sedang.Indeks keseragaman tinggi dan tidak ada dominansi jenis pada seluruh stasiun.Dari 15 jenis kepiting, terdapat 3 jenis kepiting ekonomis (Scylla serrata, Scylla olivacea dan Thalamita crenata) dan 12 jenis kepiting non-ekonomis.Secara umum, kepiting dari genus Uca merupakan kepiting yang paling banyak ditemukan di lokasi penelitian.

Kata kunci: Aceh, Keanekaragaman, Kepiting, Kuala Langsa, Mangrove 


\section{Pendahuluan}

Komunitas mangrove merupakan bagian dari ekosistem alam yang memiliki peranan penting bagi lingkungan mangrove dan sekitarnya. Menurut Saenger (2002), fungsi mangrove secara fisik yaitu mampu berperan sebagai penahan abrasi, gelombang, angin kencang bagi wilayah daratan, pengendali intrusi air laut, dan pembangun lahan melalui adanya proses sedimentasi. Fungsi secara ekologis mangrove berperan sebagai penyedia nutrien, tempat pemijahan, pembesaran, dan mencari makan (Snedaker, 1984; Nontji, 1987) dan secara ekonomis mangrove dapat dimanfaatkan sebagai kayu bakar, bahan kertas, bahan konstruksi.Bagi biota asosiasinya, mangrove mempunyai nilai eksistensi yang penting Soeroyo (1997).Menurut Hogarth (2007) fauna di mangrove ada beberapa macam diantaranya hewan yang bertulang belakang seperti amphibi, mamalia, burung, dan reptil.Dan yang tidak bertulang belakang seperti krustasea dan moluska.

Krustasea merupakan hewan makrobentos yang hidup berasosiasi dengan mangrove. Secara ekologis daerah mangrove memiliki produktivitas yang tinggi untuk mendukung lingkungan di sekitarnya karena kaya akan nutrien dengan temperatur, $\mathrm{pH}$, oksigen, dan salinitas yang optimum serta kondisi perairan yang tenang sehingga sesuai untuk dijadikan sebagai habitat krustasea (Hogarth, 2007).

Adanya interaksi antar tumbuhan dan hewan pada hutan mangrove mempunyai arti penting bagi keseimbangan populasi, komunitas dan proses yang terjadi pada tingkat ekosistem (Tomlinson, 1994).Hal ini dikarenakan vegetasi mangrove merupakan komponen yang paling dominan dalam suatu ekosistem mangrove.

Ekosistem hutan mangrove di Provinsi Aceh luasnya mencapai $63.832,99 \mathrm{Ha}$ yang banyak di wilayah pesisir timur terutama Aceh Timur, Aceh Tamiang dan Kota Langsa. Saat ini terdapat 31 jenis mangrove yang teridentifikasi di Aceh dengan kondisi rata-rata kerapatan pohon mencapai 1.811 ind/ha (BAPEDAL, 2014).

Keberadaan hutan lindung mangrove di Kuala Langsa, Kota Langsa, Aceh, telah memberikan dampak yang signifikan pada pertumbuhan dan perkembangan ekonomi masyarakat Langsa. Hutan mangrove yang dilindungi oleh peraturan daerah atau qanun Kota Langsa tersebut, berfungsi sebagai ekowisata bagi masyarakat setempat (BPS, 2012).

\section{Bahan dan Metode}

Penelitian ini dilakasanakan kawasan mangrove sekitar Pelabuhan Kuala Langsa, Kota Langsa, Provinsi Aceh pada Bulan Juli - Agustus 2017 (Gambar 1). Metode yang digunakan dengan mengumpulkan data primer.Pengumpulan data primer dilakukan melalui pengamatan dan pengambilan sampel secara langsung.

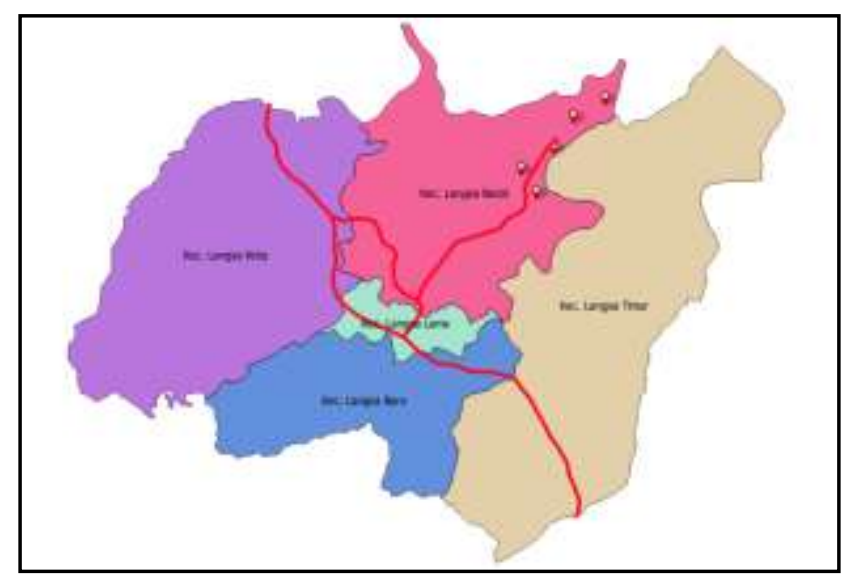

Gambar 1. Peta Lokasi Pengambilan Sampel Penelitian

Pengambilan sampel dilakukan menggunakan metode sistematika berlapis (stratified sampling method). Pengambilan sampel menggunakan teknik handpicking / mengambil dengan tangan (Dubey, Chakraborty et al., 2014, Kannupandi, Vijayakumar et al., 2003, Masagca, 2009, Shukla, Patel et al., 2013) untuk semua kepiting yang ditemukan di titik sampling yang telah ditentukan baik yang terdapat pada substrat, akar dan batang mangrove. Identifikasi kepiting menggunakan buku acuan Crosnier (1962); Crane (1975); Lovett (1981)danRahayu and Setyadi (2009).

Pada penelitian ini, data parameter fisika, kimia dan biologi perairan yang diamati adalah salinitas, suhu, pH,bahan organik dan fraksi sedimen. Pengambilan data kondisi lingkungan perairan tersebut dilakukan setelah pengambilan sampel kepiting. Data tersebut berguna untuk mendapatkan gambaran pengaruh kondisi lingkungan terhadap struktur dan keanekaragaman kepiting di lokasi penelitian.

Data keanekaragaman kepiting dianalisis berdasarkan Indeks Keanekaragaman ShannonWeaver (Odum, 1993), Indeks Keseragaman, Indeks Dominansi Simpsons (Odum, 1993) dan untuk 
menghitung kepadatan kepiting menggunakan formula Browner, Zar et al. (1990).

\section{Hasil dan Pembahasan}

\section{Komposisi kehadiran jenis kepiting}

Kepiting yang ditemukan di lokasi penelitian terdiri dari 15 spesies yang termasuk ke dalam tujuh genus (lima famili) yang berbeda, yaitu Scylla serrata, Scylla olivacea dan Thalamita crenata (Portunidae),
Uca vocans, Uca annulipes, Uca dussumieri, Uca coarctata, Uca roseaUca vomeris, Uca crypticadan Macropththalmus sp. (Ocypodidae), Metopograpsus messor dan Metopograpsus frontalis (Grapsidae), Parasesarma sp. (Sesarmidae) dan Xanthidae. Hasil penelitian ini lebih banyak jika dibandingkan dengan penelitian Muhadhir (2015)di lokasi penelitian yang sama dengan titik pengambilan sampel yang berbeda yang menemukan 2 jenis kepiting yaitu Scylla sp. dan Uca

sp.

Tabel 1. Komposisi jenis kepiting di kawasan hutan lindung mangrove Kuala Langsa.

\begin{tabular}{|c|c|c|c|c|c|c|c|}
\hline \multirow{2}{*}{ Famili } & \multirow{2}{*}{ Genus } & \multirow{2}{*}{ Jenis } & \multicolumn{5}{|c|}{ Stasiun } \\
\hline & & & $\mathbf{A}$ & $\mathbf{B}$ & $\mathbf{C}$ & $\mathbf{D}$ & $\mathbf{E}$ \\
\hline \multirow{3}{*}{ Portunidae } & \multirow{2}{*}{ Scylla } & Scylla serrata & - & - & + & + & + \\
\hline & & Scylla olivacea & - & - & + & + & + \\
\hline & \multirow[t]{4}{*}{ Thalamita } & Thalamita crenata & + & + & - & - & - \\
\hline \multirow{8}{*}{ Ocypodidae } & & Uca vocans & + & + & + & + & + \\
\hline & & Uca annulipes & + & + & + & + & + \\
\hline & & Uca dussumieri & + & + & + & + & + \\
\hline & \multirow[t]{4}{*}{$U c a$} & Uca coarctata & + & + & + & + & + \\
\hline & & Uca rosea & + & + & + & + & + \\
\hline & & Uca vomeris & + & + & + & + & + \\
\hline & & Ucacryptica & + & + & + & + & + \\
\hline & Macrophthalmidae & Macrophthalmus sp. & + & + & + & - & - \\
\hline \multirow{2}{*}{ Grapsidae } & \multirow{2}{*}{ Metopograpsus } & Metopograpsus messor & - & - & + & + & + \\
\hline & & Metopograpsus frontalis & - & - & + & + & + \\
\hline Sesarmidae & Parasesarma & Parasesarma sp. & + & + & + & + & + \\
\hline Xanthidae & - & - & + & - & - & + & - \\
\hline$\Sigma$ & 7 & & 10 & 11 & 12 & 13 & 12 \\
\hline
\end{tabular}

Keterangan : + = ditemukan, - = tidak ditemukan

\section{Kelimpahan Kepiting}

Secara umum rata-rata kelimpahan krustasea di setiap stasiun bervariasi, dan Stasiun D memiliki nilai kelimpahan paling tinggi dari stasiun lainnya 436 ind $/ 100 \mathrm{~m}^{2}$, sedangkan stasiun A memiliki kelimpahan paling rendah dibandingkan dengan Stasiun B, C dan E yaitu $364 \mathrm{ind} / 100 \mathrm{~m}^{2}$. Kondisi mangrove yang lebih baik dibandingkan stasiun lainnya. Kondisi, kerapatan, dan jenis mangrove akan berpengaruh terhadap luas penutupan kanopi dan bahan organik yang dihasilkan. 
Tabel 2. Kelimpahan Total (ind/100 $\mathrm{m}^{2}$ ) keiting di Hutan Mangrove Kuala Langsa

\begin{tabular}{|c|c|c|c|c|c|c|c|}
\hline \multirow{2}{*}{ Famili } & \multirow{2}{*}{ Genus } & \multirow{2}{*}{ Jenis } & \multicolumn{5}{|c|}{ Stasiun } \\
\hline & & & $\mathbf{A}$ & B & $\mathbf{C}$ & D & $\mathbf{E}$ \\
\hline \multirow{3}{*}{ Portunidae } & \multirow{2}{*}{ Scylla } & Scylla serrata & & & 12 & 4 & 12 \\
\hline & & Scylla olivacea & & & 8 & 8 & 4 \\
\hline & Thalamita & Thalamita crenata & 16 & 8 & & & \\
\hline \multirow{8}{*}{ Ocypodidae } & \multirow{7}{*}{$U c a$} & Uca vocans & 80 & 68 & 52 & 56 & 48 \\
\hline & & Uca annulipes & 48 & 44 & 56 & 80 & 16 \\
\hline & & Uca dussumieri & 52 & 16 & & 16 & 28 \\
\hline & & Uca coarctata & 8 & 48 & 68 & 64 & 88 \\
\hline & & Uca rosea & 48 & 60 & 64 & 48 & 40 \\
\hline & & Uca vomeris & 24 & 48 & 80 & 64 & 48 \\
\hline & & Uca cryptica & 16 & 24 & 8 & 4 & 28 \\
\hline & Macrophthalmidae & Macrophthalmus sp. & 60 & 28 & 4 & & \\
\hline \multirow[b]{2}{*}{ Grapsidae } & & Metopograpsus messor & & & 16 & 56 & 32 \\
\hline & Metopograpsus & $\begin{array}{l}\text { Metopograpsus } \\
\text { frontalis }\end{array}$ & & 20 & 28 & 12 & 16 \\
\hline Sesarmidae & Parasesarma & Parasesarma sp. & 12 & 16 & 36 & 20 & 24 \\
\hline \multicolumn{3}{|l|}{ Xanthidae } & & & & 4 & \\
\hline $\begin{array}{ll}\Sigma & 5\end{array}$ & 7 & 15 & 364 & 380 & 432 & 436 & 384 \\
\hline
\end{tabular}

Penutupan kanopi yang luas dan rapat akan menyediakan perlindungan bagi kepiting dari sengatan sinar matahari secara langsung danpredator, aksi gelombang, dan akan mempengaruhi produksi bahan organik yang dihasilkan. Tersedianya bahan organik yang tinggi pada Stasiun D (17,66 \%) akan berpengaruh terhadap organisme untuk mencari makan dan tinggal disana termasuk kepiting. Adanya karakteristik tersebut dibawah kanopi dan juga kandungan bahan organik yang tinggi menjadikan pada lokasi tersebut banyak ditemukan jenis kepiting yang berlindung dibawahnya. Selain itu, substrat pada lokasi ini berupa pasir lanauan yang tersusun dari pasir 74,53\%, kerikil 4,03\%, dan silt (lanau) 21,45\%.

\section{Keanekaragaman, Keseragaman dan Dominandi Kepiting di Hutan Mangrove Kuala Langsa}

Hasil perhitingan Indeks Keanekaragaman (H') untuk semua stasiun termasuk dalam kategori sedang. Untuk Indeks Keseragaman, stasiun A, B dan C termasuk dalam kategori tinggi, sedangkan stasiun D dan E termasuk dalam kategori rendah. Nilai Indeks Dominansi pada semua stasiun menunjukkan tidak adanya jenis yang mendominansi (TAD) (Tabel 3).

Nilai Indeks Keanekaragaman kepiting di lokasi penelitian berkisar antara 2,01-2,24Stasiun B memiliki nilai paling tinggi jika dibandingkan dengan stasiun lainnya. Jika berpatokan pada Wilhm (1975) yang mengatakan bahwa jika nilai $\mathrm{H}^{\prime}<1$, maka tingkat keanekaragamannya kecil, jika $1<\mathrm{H}^{\prime}<3$ maka masuk kategori sedang, dan jika $\mathrm{H}^{\prime}>3$ maka tergolong dalam kategori sedang.Dan secara umum nilai indeks keanekaragaman krustasea pada lokasi penelitian berada dalam kategori sedang.Dimana keanekaragaman jenis dipengaruhi oleh banyak hal, diantaranya jenis habitat tempat hidup, stabilitas lingkungan, produktifitas, kompetisi, dan penyangga rantai makanan. Nilai keanekaragaman juga menentukan maka tingkat stress atau tekanan yang diterima kepiting oleh lingkungan (Lardicci, Rossi et al., 1997). 
Tabel 3. Distribusi Nilai dan Kategori Indeks Keanekaragaman (H'), Keseragaman (e) dan Dominansi (C) di Hutan Mangrove Kuala Langsa.

\begin{tabular}{ccccccc}
\hline \multirow{2}{*}{ Stasiun } & \multicolumn{2}{c}{ Keanekaragaman } & \multicolumn{2}{c}{ Keseragaman } & \multicolumn{2}{c}{ Dominansi } \\
\cline { 2 - 7 } & H' & Keterangan & e & Keterangan & C & Keterangan \\
\hline A & 2,01 & Sedang & 0,60 & Tinggi & 0,14 & TAD \\
B & 2,24 & Sedang & 0,65 & Tinggi & 0,12 & TAD \\
C & 2,20 & Sedang & 0,61 & Tinggi & 0,13 & TAD \\
D & 2,17 & Sedang & 0,59 & Sedang & 0,13 & TAD \\
E & 2,12 & Sedang & 0,59 & Sedang & 0,12 & TAD \\
\hline
\end{tabular}

Pertambakan penduduk, rekreasi, aktivitas industri, pembuangan limbah rumah tangga, dan berbagai macam aktivitas lain seperti pelebaran lahan untuk bandara diduga menjadi salah satu faktor penyebabnya. Semakin baik kondisi lingkungan perairan, maka nilai indeks keanekaragaman jenis biota akan semakin tinggi, begitu juga sebaliknya. Indeks keanekaragaman jenis akan menurun seiring dengan menurunnya kondisi atau kualitas lingkungan perairan.

Keanekaragaman merupakan ekspresi dari variasi jenis yang ada dalam suatu ekosistem, ketika suatu ekosistem memiliki indeks keanekaragaman yang tinggi maka ekosistem tersebut cenderung seimbang. Sebaliknya, jika suatu ekosistem memiliki indeks keanekaragaman yang rendah maka mengindikasikan ekosistem tersebut dalam keadaan tertekan atau terdegradasi(Clark, 1974).

Menurut Wijaya and Pratiwi (2017), kondisi lingkungan yang menjadi tempat hidup krustases akan mempengaruhi persebarannya. Kondisi lingkungan yang sesuai akan sangat mendukung kehidupannya sehingga keberadaanya di setiap stasiun akan berbedabeda tergantung dari kondisi lingkungan dimana krustasea berada. Secara ekologis, krustasea merupakan salah satu sumber makanan penting bagi ikan dan predator lain,begitu puladengan krustasea juga sering menjadi predator bagi makhluk kecil lainnya (Pratiwi and Astuti, 2012).

Sebaliknya, jika suatu ekosistem memilki indeks keanekaragaman yang rendah maka mengindikasikan ekosistem tersebut dalam keadaan tertekan atau terdegradasi. Nilai indeks keseragaman kepiting pada penelitian ini berbeda-beda, Stasiun A $(0,60)$, Stasiun B $(0,65)$, Stasiun C $(0,61)$, Stasiun D $(0,59)$ dan Stasiun E $(0,59)$. Menurut Odum (1993), besarnya indeks keseragaman jenis berkisar antara 01. Dimana e> 0,6berkategori keseragaman jenis tinggi, jika $0,4<\mathrm{e}<0,6$ maka keseragaman jenis berkategori sedang, dan jika e $<0,4$ maka keseragaman jenis rendah. Jadi, untuk Stasiun A, B dan C termasuk dalam nilai indeks keseragaman jenis tinggi sedngkan untuk Stasiun D dan Stasiun E masuk kedalam kategori keseragaman jenis rendah. Dan untuk nilai indeks dominasi pada lokasi penelitian ini tidak ditemukannya jenis yang mendominasi pada seluruh stasiun pengamatan (TAD) (Tabel 3).

\section{Parameter Lingkungan}

Parameter lingkungan pada setiap stasiun penelitian secara umum menunjukkan bahwa sebagian data cukup variasi dan sebagian kurang bervariasi antar lokasi. Nilai parameter lingkungan yang diukur meliputi suhu $\left({ }^{\circ} \mathrm{C}\right)$ derajat keasaman $(\mathrm{pH})$, dan salinitas (\%) yang diukur dari air pori sedimen. Hasil pengukuran parameter lingkungan pada lokasi penelitian memiliki suhu rata-rata bekisar antara 26 $29^{\circ} \mathrm{C}$, suhu rata-rata terendah berada pada Stasiun D. Diduga bedanya suhu rata-rata tiap stasiunnya dipengaruhi oleh tutupan vegetasi mangrove disekitarnya, jenis sedimen, dan waktu sampling penelitian. 
Tabel 4.Nilai Paramater Lingkungan di Vegetasi Mangrove Kuala Langsa

\begin{tabular}{llcccccc}
\hline \multirow{2}{*}{ No. } & & \multirow{6}{*}{ Parameter } & Satuan & \multicolumn{6}{c}{ Stasiun Pengamatan } \\
\cline { 4 - 8 } & & & $\mathrm{A}$ & $\mathrm{B}$ & $\mathrm{C}$ & $\mathrm{D}$ & $\mathrm{E}$ \\
\hline 1 & $\mathrm{pH}$ & - & 6,17 & 7,79 & 9,05 & 8,04 & 8,13 \\
2 & Kedalaman substrat & $\mathrm{cm}$ & 25 & 17 & 10 & 10 & 12 \\
3 & Suhu & ${ }^{\circ} \mathrm{C}$ & 28 & 29 & 26 & 26 & 26 \\
4 & Salinitas & $\%$ & 33 & 32 & 30 & 30 & 29 \\
5 & Kerikil & $\%$ & 0,97 & 3,69 & 8,41 & 4,02 & 8,41 \\
6 & Pasir & $\%$ & 84,8 & 75,75 & 73,33 & 74,53 & 73,33 \\
7 & Lanau & $\%$ & 14,23 & 20,56 & 18,26 & 21,45 & 18,26 \\
8 & Kerapatan mangrove & ind./ha & 723 & 3212 & 3769 & 3923 & 3537 \\
\hline
\end{tabular}

Faktor lingkungan yang paling berpengaruh pada penelitian ini adalah bahan organik, dimana kondisi mangrove mempengaruhi banyak sedikitnya bahan organik.Semakin baik kondisi vegetasi mangrove maka semakin tinggi kandungan bahan organiknya, bahan organik berperan sebagai sumber makanan dan energi bagi mikroorganisme.

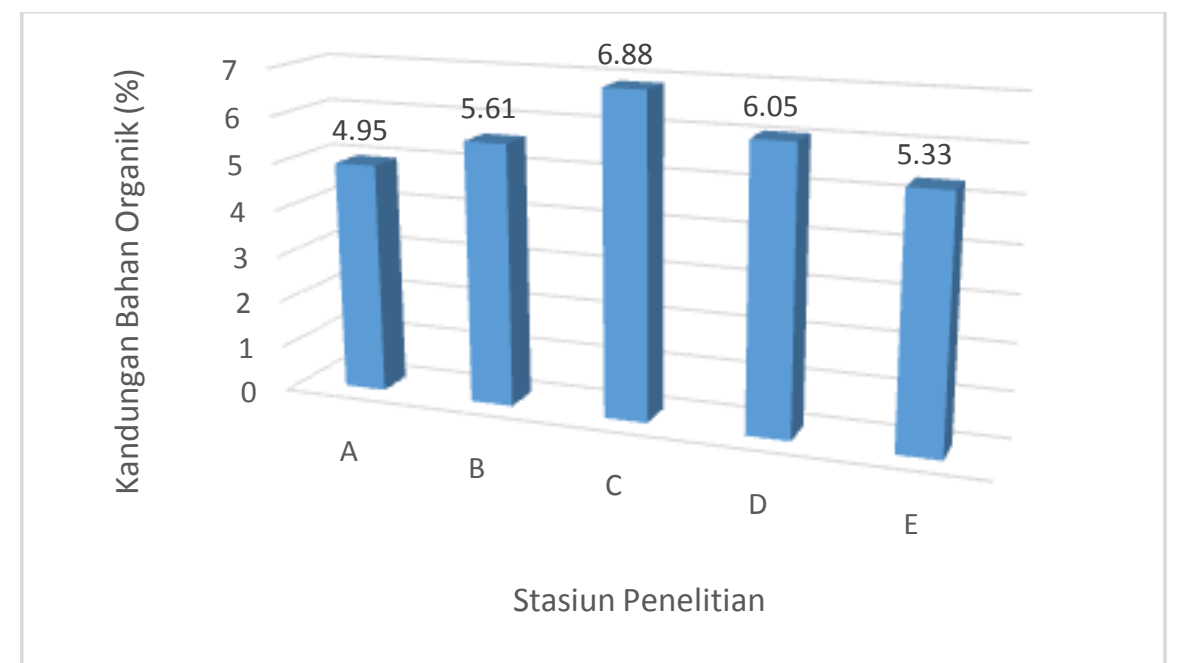

Gambar 2. Kandungan Bahan Organik Pada Setiap Stasiun Penelitian di Vegetasi Mangrove Kuala Langsa.

Pada stasiun $\mathrm{C}$, kandungan bahan organiknya paling tinggi jika dibandingkan dengan stasiun yang lain (Gambar 2).Diduga dengan semakin tingginyakandungan bahan organik yang terdapatpada suatu lokasi penelitian akanmenyebabkan banyak ditemukannyamikroorganisme pada lokasi tersebut.Kelimpahan konsumen pada taraf tropiyang lebih tinggi secara tidak langsung didukung oleh keberadaan mikroorganisme tersebut(Kohnke, 1968).

Peristiwa ini akan menyebabkanjumlah makanan bagi krustaseameningkat. Banyaknya jumlah makananyang tersedia secara otomatis didugaakan berpotensi dalam kebutuhan nutrisibagi krustasea.

\section{Kesimpulan}

Pada penelitian ini, ditemukan 15 jenis kepiting dari 5 famili (7 genus). Rata-rata keanekaragaman jenis kepiting pada lokasi penelitian termasuk dalam kategori sedang. Untuk Indeks keseragaman termasuk dalam kategori sedang dan pada seluruh lokasi penelitian tidak ditemukannya kepiting yang mendominansi. Hanya saja, kepiting dari Genus Uca paling sering dijumpai pada tiap lokasi penelitian. Kepiting yang paling sering 
dijumpai adalah kepiting dari genus Ucadengan substrat pasir berlumpur.

\section{Ucapan Terima Kasih}

Penulis mengucapkan terima kasih kepada Ditjen Risbang Kemenristek Dikti yang telah memberikan dana penelitian dan semua pihak terkait yang telah membantu sehingga penelitian ini berjalan lancar.

\section{Daftar Pustaka}

BAPEDAL (2014). Laporan Status Lingkungan Hidup Daerah Provinsi Aceh. ACEH, BAPEDAL.

BPS (2012). STATISTIK DAERAH KOTA LANGSA 2015 Langsa, Badan Pusat Statistik Kota Langsa. 31 hal.

Browner, J.E., Zar, J.H. \& Ende, C.N.v. (1990). Field and Laboratory Methods For General Ecology. In W. M. Brown ed. Iowa.

Clark, J. (1974). Ecological Considerations For Management of The Coastal Zone. Washington D.C: Publications Departement The Concervations Foundation.

Crane, J. (1975). Fiddler Crabs Of The World (Ocypodidae: Genus Uca). Princeton, N.J.,: Princeton University Press.

Crosnier, A. (1962). Décapodes, Crustacés : Portunidae. Fauna de Madagascar 16 1-154.

Dubey, S.K., Chakraborty, D.C., Bhattacharya, C. \& Choudhury, A. (2014). Allometric Relationships of Red Ghost Crab Ocypode macrocera (H. Milne-Edwards, 1852) in Sundarbans Mangrove Eco-Region, India. World 6(2) 176-181.

Kannupandi, T., Vijayakumar, G. \& Soundarapandian, P. (2003). Yolk Utilization In a Mangrove Crab Sesarma brockii (De Man). Indian J. Fish. 50(2) 199-202.

Lardicci, C., Rossi, F. \& Castelli, A. (1997). Analysis Of Macrozoobenthic Community Structure After Severe Dystrophic Crises In a
Mediterranean Coastal Lagoon. Mar Pollut Bull 34(7) 536-547.

Lovett, D.L. (1981). A Guide to The Shrimps, Prawns, Lobsters, and Crabs of Malaysia and Singapore: Faculty of Fisheries and Marine Science, Universiti Pertanian Malaysia.

Masagca, J.T. (2009). Feeding Ecology Of TreeClimbing Mangrove Sesarmid Crabs From Luzon, Philippines. BIOTROPIA 16(1) 1-10.

Muhadhir (2015). Struktur Komunitas Makrozoobenthos Yang Berasosiasi Dengan Ekosistem Mangrove Di Perairan Kuala Langsa, Kota Langsa. FAKULTAS KELAUTAN DAN PERIKANAN. BANDA ACEH, UNIVERSITAS SYIAH KUALA.

Odum, E.P. (1993). Fundamentals of Ecology. In T. Samingan ed. Yogyakarta (ID), Gadjah Mada University Press.

Pratiwi, R. \& Astuti, O. (2012). Biodiversitas Krustasea (Decapoda, Brachyura, Macrura) dari Ekspedisi Perairan Kendari 2011 (Biodiversity of Crustacean (Decapoda, Brachyura, Macrura) from Kendari Waters Expedition 2011). ILMU KELAUTAN: Indonesian Journal of Marine Sciences 17(1) 8-14.

Rahayu, D.L. \& Setyadi, G. (2009). Mangrove Estuary Crabs of the Mimika Region-Papua, Indonesia. Jakarta: PT. Freeport Indonesia.

Shukla, M., Patel, B., Trivedi, J. \& Vachhrajani, K. (2013). Brachyuran Crabs Diversity of Mahi and Dhadhar Estuaries, Gujarat, India. Research Journal of Marine Sciences 2321 1296.

Tomlinson, P.B. (1994). The Botany of Mangroves. Cambridge (UK): Cambridge University Press.

Wijaya, N.I. \& Pratiwi, R. (2017). Distribusi spasial krustasea di perairan kepulauan Matasiri, Kalimantan Selatan. Jurnal Pertanian Terpadu 92-108. 